\title{
THE EFFECTS OF AGE ON BARORECEPTOR REFLEX FUNCTION IN MAN
}

\author{
Peter C. Duke, "John G. Wade, "Robert F. Hickey, $\nmid$ and C. Philip Larson $\nmid$
}

IT IS WELL KNOWN that baroreceptor reflex activity is an important factor in the acute homeostatic regulation of the cardiovascular system, particularly under stressful conditions such as haemorrhage or sudden postural changes. ${ }^{1-4}$ Despite the numerous changes observed in cardiovascular structure and function that occur with aging, ${ }^{5-13}$ the relationship between aging and baroreceptor reflex function has not been clarified. Earlier work by Norris, et al. ${ }^{14}$ using tilting techniques observed reflex changes in heart rate and blood pressure in normal subjects and ambulatory patients ranging in age from 20 to 92 years. The elderly subjects showed the greatest decrease in blood pressure with the least change in heart rate, suggesting that with aging there is some alteration in the reflex regulation of the cardiovascular system.

Wade, et al., utilizing the Valsalva maneuver to quantitate baroreceptor reflex function, showed the baroreceptor reflex activity appeared to decrease with age. ${ }^{15}$ However, a majority of patients studied had some clinically significant occlusive cerebral vascular disease. In three recent studies utilizing techniques of stressing the baroreceptor mechanisms by pharmacologically induced hypertension, Bristow, et al., ${ }^{16}$ Eckberg, et al., ${ }^{17}$ and Gribbin, et al. ${ }^{18}$ found a negative correlation between baroreceptor reflex function and age. Bristow, et al. studied normotensive and hypertensive subjects. Baroreflex function was decreased in their hypertensive subjects. An inverse relationship between age and baroreflex function was apparent when all subjects were considered irrespective of their baseline blood pressures. In Eckberg's studies, a similar relationship between age and baroreceptor reflex function was observed in 23 subjects with no demonstrable cardiovascular disease. The majority of their controls ( 15 subjects) were between the ages of 15 and 30 years. Because only 3 subjects were over the age of 45 years, we felt that the age spectrum covered was inadequate. Gribbin, et al. observed that baroreflex sensitivity was independently reduced by increasing age and blood pressure in a larger number of subjects than the latter study. The purpose of this present study was to examine the relationship between aging and baroreflex function in man by utilizing two quantitative tests of baroreflex function. The traditional Valsalva maneuver test as described by Sharpey-Schafer, ${ }^{19}$ which stimulates the baroreflex by producing a transient arterial hypotension and the pressor test described by Smyth, Sleight, and Pickering, ${ }^{20}$ which is based on producing a baroreflex response to pharmacologically induced hypertension.

- Department of Anaesthesia, University of Manitoba, Winnipeg, Manitoba, Canada.

†Department of Anaesthesia, University of California, San Francisco, California, U.S.A. 94122.

Supported by grants from The Medical Research Council of Canada and N.I.H. Clough Award. 


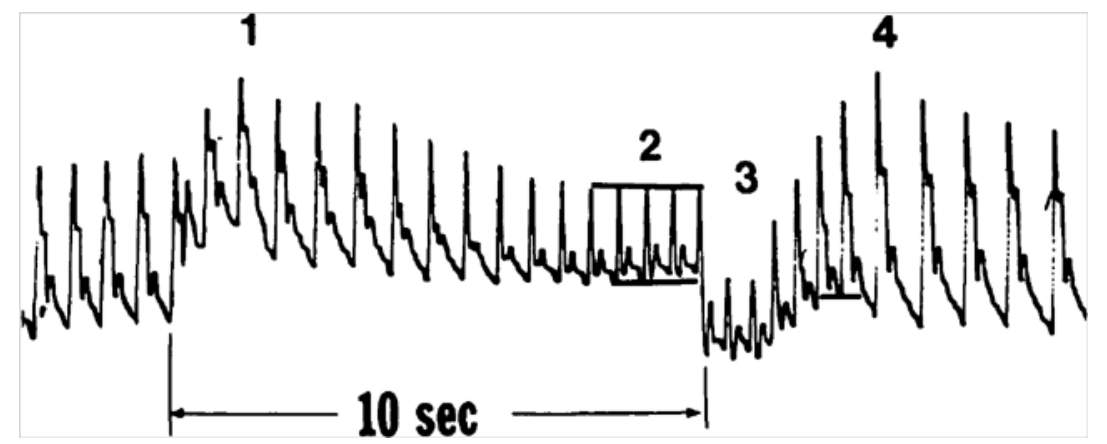

Figure 1. Typical arterial blood pressure record with the various phases of a 10 -second Valsalva maneuver. The test is quantitated by relating the per cent pulse pressure decrease in Phase 2 (baroreceptor stimulus) to the per cent increase in diastolic overshoot occurring in Phase 4 (the cardiovascular response). Values are expressed as a percentage of controls.

\section{Methods}

The two tests of baroreceptor reflex function (B.R.F.) were performed on 35 healthy unmedicated volunteers ranging in age from 19 to 65 years. Consent for performing all studies was in accordance with the institutional policies on human experimentation. The Valsalva maneuver was performed by 31 subjects and 33 subjects underwent pressor testing. On 29 subjects both tests were studied. All subjects were defined as normal by history, physical examination, cuff blood pressure and electrocardiogram, absence of orthostatic hypotension and normal arterial blood gases and $\mathrm{pH}$. All subjects were studied in the supine position with a $30^{\circ}$ headup tilt. The brachial or radial artery was catheterized percutaneously under local anaesthesia with an 18 gauge polyethylene catheter." The catheter was connected to a Statham P23 D e strain gauge and the transducer signal was amplified and recorded with a direct writing polygraph. Mechanical and electrical calibrations were carried out with each experiment. Lead 2 or a standard threelimb electrocardiogram was simultaneously recorded on the polygraph.

The Valsalva maneuver consists of a forced expiration sufficient to raise a column of mercury 40 torr for ten seconds (glottis open), during which time direct arterial blood pressure is recorded. The baroreceptor stimulus expressed as a per cent decrease in pulse pressure occurring during forced expiration (phase 2) is plotted against the per cent increase in diastolic pressure occurring during the overshoot phase (phase 4) as in Figure 1. Duplicate studies were performed on each subject and the results were averaged. The data for each subject were plotted against the "normal" range as described by Sharpey-Schafer. ${ }^{19}$ For comparison, all subjects were divided arbitrarily into three age groups. Group 1: age 20 to 29, Group 2: 30 to 49 , and Group 3: age 50 to 65 . The mean and standard errors of each parameter of each designated age group were calculated and compared to one another by utilizing a one-way analysis of variance ( $F$ ratio) and the least significant difference test (LSD) to the 5 per cent level. These tests enabled one to differentiate several subgroups within a population from one another statistically.

•Argyle medicut. 


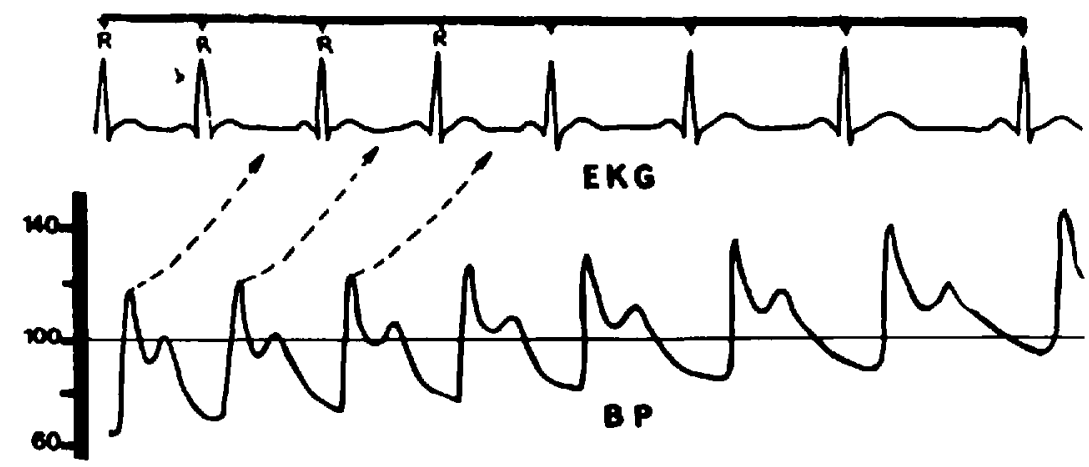

REFLEX BRADYCARDIA DUE TO INCREASE IN BLOOD PRESSURE

Figure 2. Rising systolic pressure reflexly induces cardiac slowing. Each systolic pressure is plotted against its immediately succeeding $\mathrm{R}-\mathrm{R}$ interval, expressed in milliseconds, as the pressure increases.

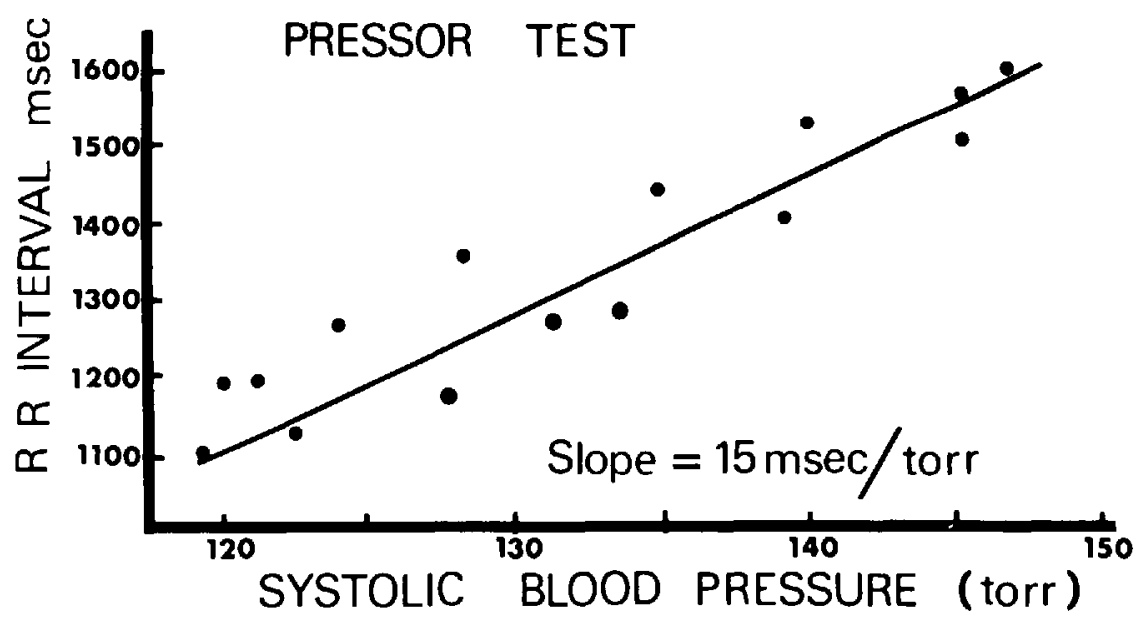

Figure 3. Systolic blood pressure (abscissa) plotted against the succeeding R-R interval (ordinate) for one subject. The relationship between the two parameters is represented by the computed line. The slope of this line expressed in milliseconds of $R-R$ interval change per torr rise in systolic pressure is a quantitation of BRF.

The details of the pressor test have been described elsewhere ${ }^{16,20}$ and only an abbreviated description will be presented here. A hypertensive stimulus sufficient to raise the systolic blood pressure 20 to 25 torr or to lengthen the pulse interval is produced by a rapid intravenous bolus injection of a direct smooth muscle vasoconstrictor (either phenylephrine or angiotensin). Direct arterial blood pressure and electrocardiogram are simultaneously recorded. The systolic pressure and succeeding R-R interval (expressed in milliseconds) prior to and during the initial pressure rise is determined (Figure 2). As the systolic pressure increases, the R-R interval lengthens. A linear relationship exists between these two parameters and by the method of least squares a slope is calculated and expressed in R-R interval change, in milliseconds per torr increase in systolic pressure (Figure 3). A steep 


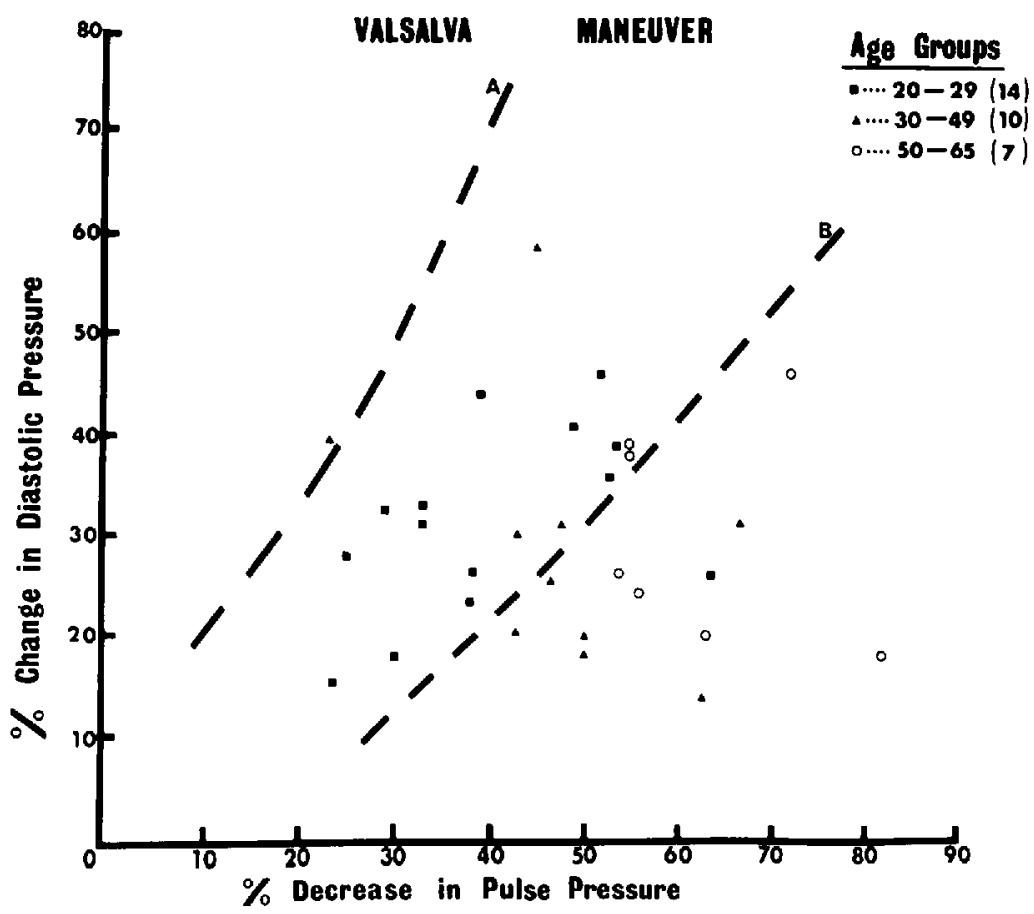

Figure 4. Per cent decrease in pulse pressure plotted against the per cent change in diastolic pressure occurring during the overshoot phase. The scatter of subjects of each designated age group is shown in relationship to the previously described normal limits between dashed lines $A$ and $B$ (see text). Note the distinct difference in distribution of the young subjects and elderly subjects.

slope represents active baroreflex function, since a small increase in systolic pressure causes marked cardiac slowing. Conversely, a flat slope represents depressed baroreflex function, as a large increase in systolic blood pressure produced little cardiac slowing.

The pressor test was performed on 33 healthy subjects ranging in age from 19 to 65 years. Baseline systolic blood pressure and electrocardiogram were recorded simultaneously. Phenylephrine in a dose range from 0.25 to 0.75 milligrams was injected rapidly into a large vein and forced in by a rapid intravenous infusion of 5 per cent dextrose and water. Sensitivity was tested in each subject by the injection of graded doses of the vasopressor. Studies were made in duplicate and the results were averaged. The resulting slopes were then plotted against each subject's respective age. All slopes with correlation coefficients below 0.78 or a probability value derived from the correlation coefficient of more than 0.05 were excluded (one subject only). All subjects were then divided arbitrarily into similar age groups as described for the Valsalva maneuver studies and their data were subjected to similar statistical analysis.

\section{Results}

The relationship between the per cent decrease in pulse pressure and per cent change in diastolic pressure for each subject is plotted in Figure 4. The area be- 


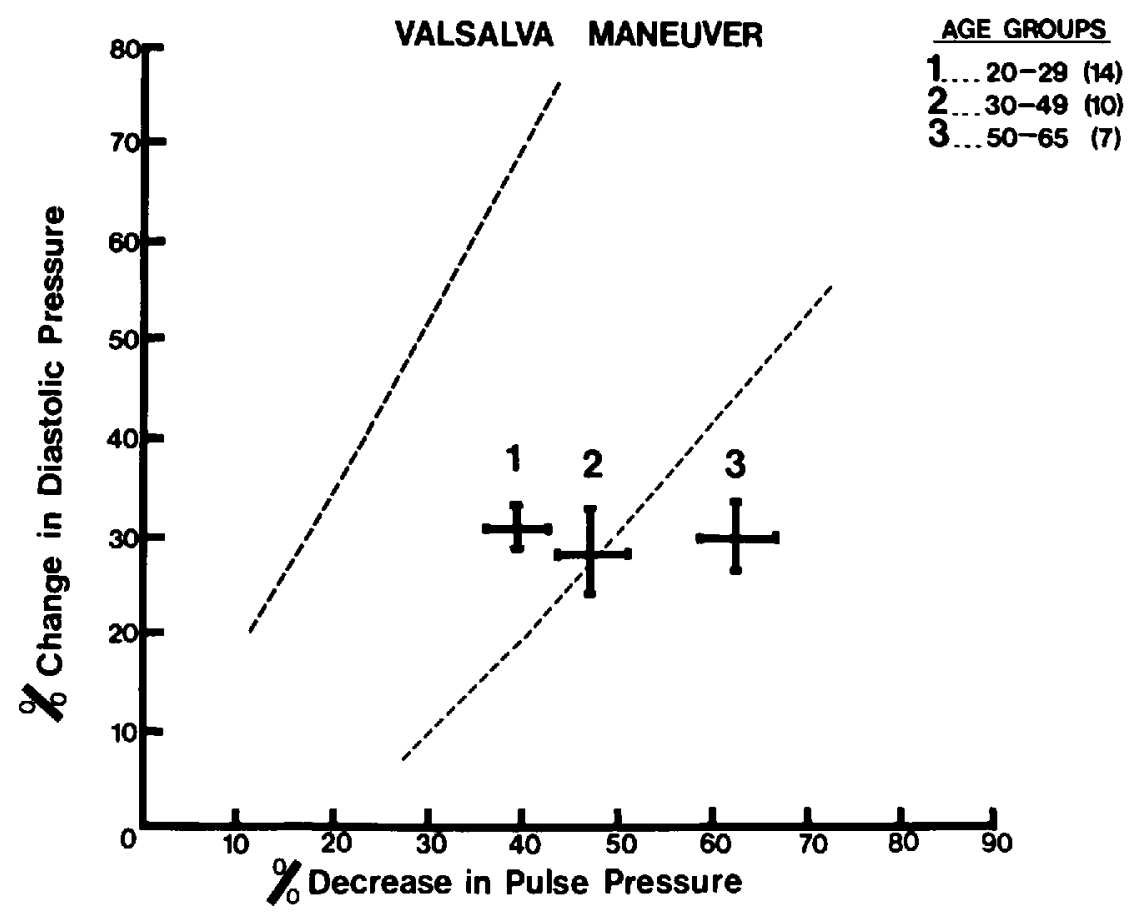

Figune 5. Mean and standard error of each parameter of each age group is compared to one another. There is no significant difference between the per cent diastolic overshoot of the age groups $(p>0.05)$. However, with per cent decrease in pulse pressure, Groups 1 and 3 and Groups 2 and 3 differ statistically $(p<0.05)$. This does not hold true for Groups 1 and 2.

tween the dashed lines A and B represents the normal range as described by Sharpey-Shafer from observations obtained from 360 healthy subjects ranging in age from 13 to 25 years. ${ }^{19}$ Despite the considerable overlap in the three designated age groups, most values for Group 3 lie to the right of the proposed normal range. All but one of the younger age group (Group 1) lies within the proposed normal limits. The Group 2 subjects are distributed between the normal range and the area to the right of Line $\mathrm{B}$. Figure 5 relates the mean \pm standard error of each parameter of each age group. Statistically there is no difference between the mean per cent diastolic overshoots in the three groups. However, the mean per cent decrease in pulse pressure occurring during phase 2 or the Valsalva maneuver in each group is significantly different when comparing Group 1 to 3 and Group 2 to 3 . This does not hold true when comparing Group 1 to 2 .

Figure 6 shows the slope calculated from the Pressor Test plotted against age for each subject. With aging, baroreflex function decreases when measured in terms of heart rate slowing. This is most marked in those individuals over 50 years of age. Because the relationship obtained was almost hyperbolic, we plotted age against the reciprocal of slope for each volunteer. A linear relationship exists (correlation coefficient 0.84 ) as shown in Figure 7. When the subjects were arbitrarily divided into age groups as designated in Figure 8, the mean values obtained for each group were significantly different from one another $(\mathrm{p}<0.05)$. 


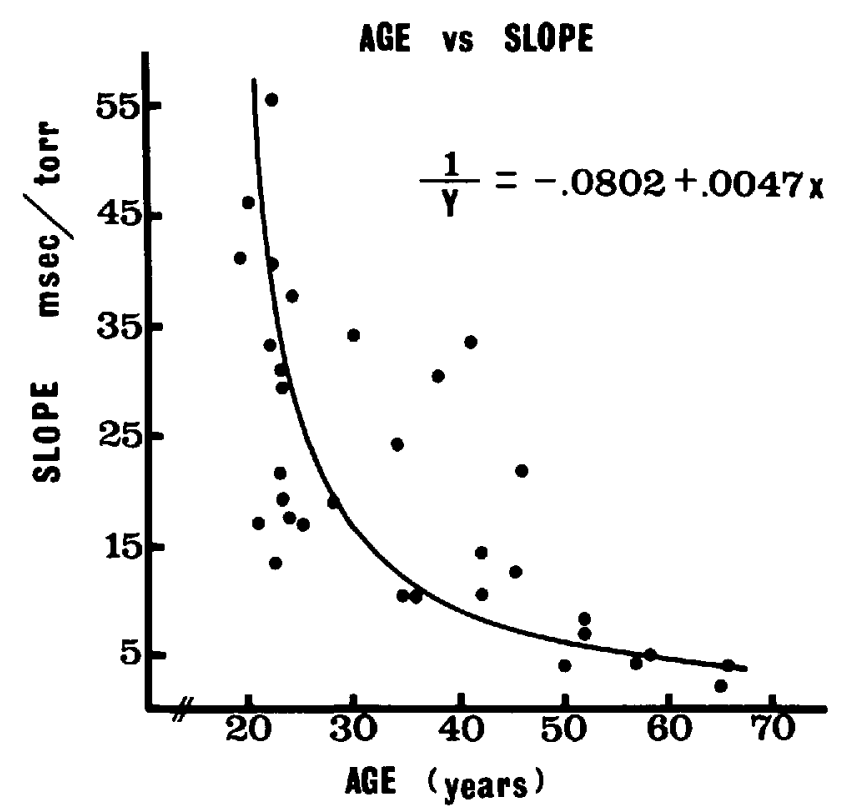

Figure 6. Age (abscissa) plotted against each subject's slope (ordinate). The relationship between age and slope is almost hyperbolic. The continuous line represents the equation $1 / y=$ $-0.0802+0.0047 x$.

\section{Discussion}

Our data indicate that with advancing age baroreflex function decreases. The Valsalva maneuver test shows that in order to produce the same mean per cent change in diastolic overshoot a greater stimulus to the baroreceptor (pulse pressure decrease) is required in the older age group (i.e. Group 3 require 22 per cent greater blood pressure decrease than Group 1). The observation that our results for the Valsalva maneuver test do not fall into the normal range as defined in Figure 4 can be explained on the basis that the 360 normal subjects studied by Sharpey-Schafer ranged in age from 13 to 25 years. ${ }^{19}$ An age effect on the Valsalva maneuver test similar to our observations has been previously described by Appenzeller and Descarries. $^{21}$ They studied 39 subjects ranging in age from 13 to 82 years. Twenty of the subjects over the age of 40 years fell outside of the "normal" range. The blood pressure response to the Valsalva maneuver was recorded either directly from a scalp vein filled with Heparin and connected to a Statham P23 pressure transducer and recorded on a polygraph or by direct visualization from height of the pulsations of the column of blood in a sealed plastic tubing of the scalp vein set. The latter method obviously has some technical problems. Further, all subjects studied were hospitalized patients without clinical evidence of cerebral vascular disease. There was no mention of the clinical disorders or medications the "normal" patients had been receiving. This may have some effect on the responses obtained during the Valsalva maneuver studies. Their observations must be interpreted with caution.

Numerous investigations have utilized the Valsalva maneuver test as a measure 


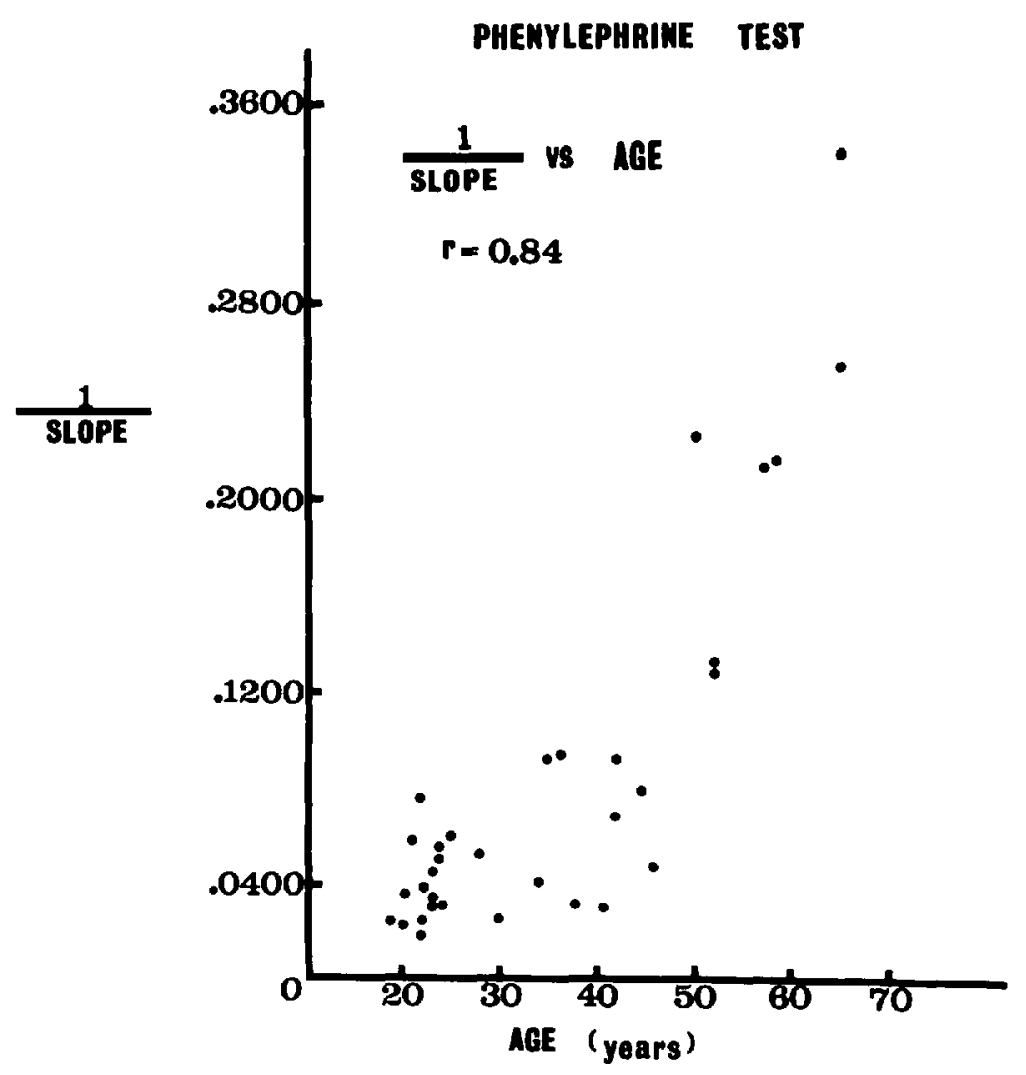

Figure 7. The relationship between age and the reciprocal of each subject's slope shows an excellent correlation ( $R=0.84$ ). Aging reduced baroreflex function in terms of heart rate changes particularly in subjects above 50 years.

of the integrity of the cardiovascular system and in particular baroreflex function. Altered baroreflex function has been observed during anaesthesia and mechanical ventilation, ${ }^{22.23}$ in patients with congestive heart failure ${ }^{19}$ diabetic and alcoholic neuritis ${ }^{24,25}$ in congenital and acquired heart disease, ${ }^{26}$ following the administration of psychotropic and barbiturate drugs ${ }^{25}$ and with the numerous other pharmacological agents which have their main effect on the autonomic nervous system. ${ }^{26,27}$ Many of these studies were performed on subjects over 40 years of age. Thus, some of the conclusions reached by these authors may be in part erroneous if the effect of aging on the Valsalva maneuver which we have observed has not been taken into consideration.

Despite our findings, we feel that the Valsalva maneuver test as a measure of intact baroreflex mechanisms must be interpreted with caution. We found it poorly reproducible, probably for several reasons. (1) It requires active participation and co-operation from the patient. Expiration with a partially closed glottis, poor blowing with excessive air leak around the mouthpiece and inability to maintain a constant pressure against the mercury column can lead to variable results. We attempted to eliminate these technical problems in our study; however, we cannot be certain that some did not occur. (2) Despite our efforts to maintain basal condi- 


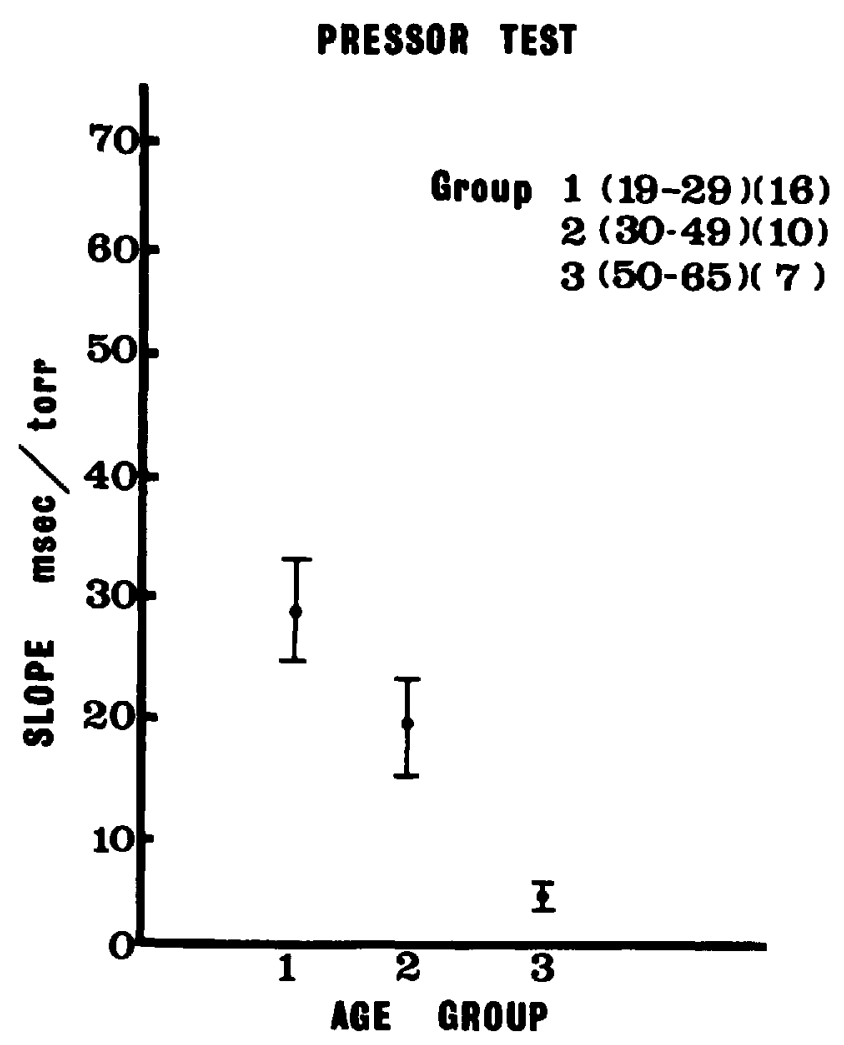

FIGUnE 8. Mean slope \pm S.E. of each age group is compared. They are significantly different from one another $(\mathrm{p}<0.05)$.

tions throughout the experimental procedures, some of the individuals exhibited signs of anxiety and apprehension as indicated by heart rate and blood pressure increases occurring during the baseline period, suggesting an increase in sympathetic tone. This could affect venous filling pressure of the heart and thus minimize the blood pressure responses occurring during phase 2 of the Valsalva maneuver. ${ }^{10.27}$ Hyperventilation prior to the test has also been shown to markedly reduce the pulse pressure occurring during phase 2 of the Valsalva maneuver, with a greater increase in the diastolic overshoot occurring during phase $4 .{ }^{28}$ Although arterial blood gases were monitored in most of the subjects at some period during our studies and despite each subject usually being normocapnic, we cannot guarantee that a particular subject was not hyperventilating immediately prior to the Valsalva maneuver test. (3) Other factors that alter intrapulmonic pressures such as position of the diaphragm, intra-abdominal and intra-gastric pressure, and the depth of inspiration prior to the Valsalva maneuver had been shown to affect this test. ${ }^{29}$ Attempts were made to standardize the size of inspiration prior to the Valsalva maneuver; however, this was not rigidly controlled.

The pressor test as a quantitative measure of baroreflex function has been discussed in detail by Smyth, et al. ${ }^{20}$ and Bristow, et al. ${ }^{16}$ The test has been utilized to show that BRF is altered in various situations in man. It's sensitivity is increased 
during normal sleep. ${ }^{20}$ It is decreased in subjects with hypertension, ${ }^{16.18}$ various forms of acquired and congenital heart disease, ${ }^{17}$ during halothane $e^{31,32}$ and barbiturate $^{32}$ anaesthesia. It is only slightly depressed in hyperoxic hypercapnic subjects. ${ }^{30}$ The sensitivity is unchanged in hyperoxic hypocapnic subjects, ${ }^{31}$ hypoxic hypercapnic subjects ${ }^{30}$ or subjects anaesthetized to light or moderate depths of methoxyflurane anaesthesia. ${ }^{33}$ Our studies indicate an excellent relationship between age in baroreceptor reflex function in terms of cardiac slowing. This relationship has been alluded to by two other independent studies by Bristow, et al. ${ }^{16}$ and Eckberg, et al. ${ }^{17}$ Bristow, et al. found that baroreceptor slopes were markedly depressed in chronically hypertensive subjects but not in normotensive patients. The average age of this latter group was approximately six years greater than the control group and the investigators suggested that age alone may have some effect on their results. If one looks at the slopes of their normal subjects over 47 years (five subjects), a mean slope of $5.97 \mathrm{msec} /$ torr is obtained. This is similar to the mean slope obtained in our Group 3 subjects (mean slope $=5.2 \mathrm{msec} /$ torr). Eckberg, et al., ${ }^{17}$ in comparing changes in autonomic control of the heart in normal and cardiac patients, found that there was a significant negative correlation between baroreflex slope and age $(p<0.05)$ in their normal control subjects. In a larger study Gribbin, et al. ${ }^{18}$ observed a curvilinear relationship between increasing age and decreasing baroreflex activity similar to our pressor test results.

Bristow, et al. ${ }^{16}$ and Gribbin, et al. ${ }^{18}$ have shown that BRF sensitivity is decreased in the presence of chronically elevated blood pressure. The normal elevation of blood pressure with aging has been well documented. ${ }^{2,3}$ We therefore related the mean slope of each subject (all who were normotensive) to his respective resting systolic pressure (Figure 9). Although the correlation between these two parameters was poor $(R=-0.42)$, we cannot rule out some blood pressure effect on our results.

It should be re-emphasized that the pressor test quantitates BRF only in terms of cardiac slowing and tells us very little about the other parameters involved in the reflex, such as change in venomotor tone and myocardial contractility.

In comparison of these two quantitative measurements of baroreflex responses, the pressor test appears to be superior. It requires little patient co-operation and is easily reproducible.

The results obtained from these two tests tend to complement one another as the Valsalva maneuver test measures the response to a decrease in pulse pressure to the baroreceptor areas, whereas the pressor test represents a response to increase in blood pressure.

Both tests indicate that aging has a significant effect on overall baroreceptor reflex function. In lieu of this, it must be emphasized that these data offer no insight into where the locus of altered sensitivity prevails. However, several structural and physiological alterations have been observed in various parts of the reflex in man with aging.

Degenerative structural changes with aging and "stiffening" of the arterial wall have been well documented. ${ }^{37-39.10,35}$ This increased resistance to deformation could result in less distortion of the arterial wall and hence less baroreceptor stimulation for a given pressure rise in the older subjects. Muratori ${ }^{40,41}$ has pointed 


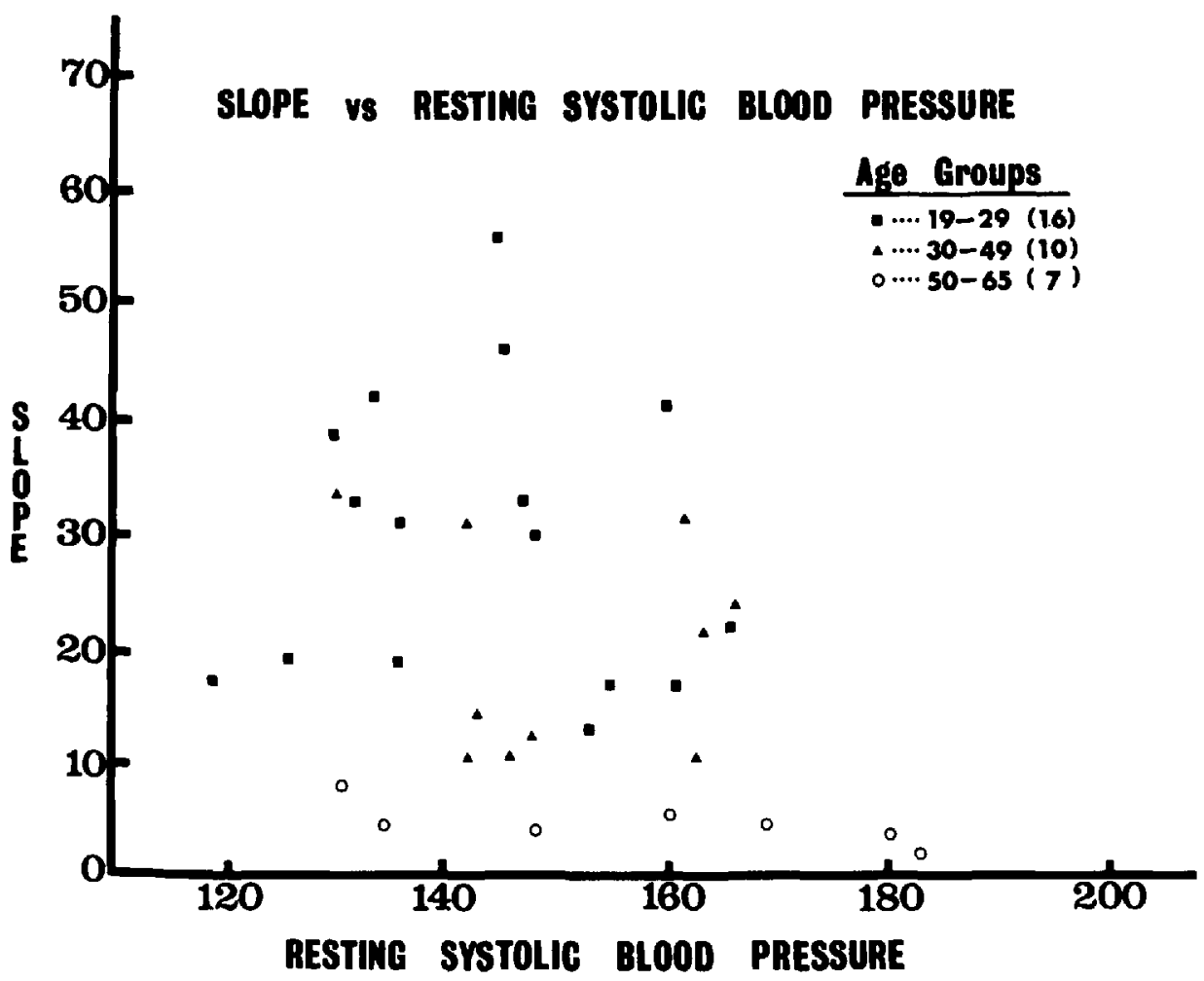

FICURE 9. Slope of each subject and the respective resting systolic blood pressure of each subject is compared. The correlation between the two parameters is poor ( $R=-0.42)$.

out that in children and newborn infants the carotid sinus is a functional rather than an anatomical occurrence, whereas in older subjects the opposite is true. His explanation is that between the ages of 40 and 50 years, the elastic arteries dilate and become permanently distended. This suggests that compliance changes have taken place in this area with aging which would offer more resistance to distortion. Further, Abraham ${ }^{42}$ has shown that aging produces deformation and definite structural changes in nerve ending systems in the wall of the human carotid sinus and aortic arch. These anatomical changes may account in part for the functional changes we have observed with aging.

Observations on how aging affects the central nervous system components and efferent baroreflex pathways and correlations between anatomic and functional changes in these areas is lacking. Degenerative changes in the central nervous system $^{50.51}$ and ganglionic cells ${ }^{52}$ have been observed. Decreasing autonomic function has been noted in all elderly subjects following tilting from horizontal to vertical position ${ }^{14}$ and following the administration of atropine. ${ }^{55}$ Despite these studies and our observations, we can offer no insight into where the locus or loci of altered baroreflex response occurs with aging. 
TABLE I

Data for Valsalva Maneuver Test and Pressor Test Divided into Three Arbitrary Groups

\begin{tabular}{|c|c|c|c|c|c|}
\hline \multirow[b]{3}{*}{ Subject } & \multirow[b]{3}{*}{ Age } & \multicolumn{2}{|c|}{ Valsalva Test } & \multirow{2}{*}{\multicolumn{2}{|c|}{ Pressor Test }} \\
\hline & & \multirow{2}{*}{$\begin{array}{l}\text { Per cent } \\
\text { pulse } \\
\text { pressure } \\
\text { decrease }\end{array}$} & \multirow{2}{*}{$\begin{array}{c}\text { Per cent } \\
\text { diastolic } \\
\text { pressure } \\
\text { overshoot }\end{array}$} & & \\
\hline & & & & $\begin{array}{l}\text { Mean } \\
\text { slope }\end{array}$ & $\begin{array}{l}\text { Correlation } \\
\text { coefficient } \\
\text { (R) }\end{array}$ \\
\hline \multicolumn{6}{|l|}{ Group 1} \\
\hline$\underset{\mathrm{PS}}{\mathrm{H}}$ & 24 & 63.5 & 26 & 17.98 & 0.92 \\
\hline PS & 22 & 23 & 19 & 29.70 & 0.83 \\
\hline GN & 23 & 33 & 31 & 29.87 & 0.82 \\
\hline $\mathrm{AG}$ & 22 & & 33 & 55.79 & 0.88 \\
\hline $\begin{array}{l}\text { BW } \\
\text { GV }\end{array}$ & 21 & 54 & 38.5 & 17.10 & 0.91 \\
\hline$\underset{\text { GV }}{\text { GR }}$ & 23 & 30 & 17.5 & 31.26 & 0.82 \\
\hline SR & 22 & 38 & 23 & 41.08 & 0.83 \\
\hline$B G$ & $2 \overline{3}$ & 38.5 & 43.5 & 21.97 & 0.82 \\
\hline $\mathrm{BR}$ & 22 & 48.5 & 41 & 33.14 & 0.89 \\
\hline $\mathrm{RT}$ & 25 & 53 & $35 . \overline{5}$ & 16.99 & 0.88 \\
\hline$\underset{\mathrm{RF}}{\mathrm{CS}}$ & 22 & 52 & 46 & & \\
\hline RF & 23 & 29.5 & 31 & 19.28 & 0.85 \\
\hline CS & 28 & 38.5 & 26.5 & 19.39 & 0.78 \\
\hline$A L$ & 24 & 25 & 25 & 38.08 & 0.93 \\
\hline RF & 20 & - & - & 46.58 & 0.83 \\
\hline RS & 22 & - & - & 13.17 & 0.89 \\
\hline$\underline{W G}$ & 19 & - & - & 41.29 & 0.88 \\
\hline$\overline{\mathrm{X}} \pm \mathrm{SE}$ & $22.7 \pm 0.5$ & $40.0 \pm 3.3$ & $31.2 \pm 2.4$ & $29.56 \pm 3.11$ & \\
\hline \multicolumn{6}{|l|}{ Group 2} \\
\hline $\mathrm{BW}$ & 35 & 67 & 31 & & \\
\hline GD & 45 & 50 & 20 & 12.73 & 0.90 \\
\hline $\mathrm{RD}$ & 42 & 63 & 14 & 10.85 & 0.95 \\
\hline PD & 30 & & & 34.03 & 0.94 \\
\hline GB & 41 & 46 & 59 & 33.38 & 0.79 \\
\hline $\mathrm{AR}$ & 42 & 23 & 39 & 14.60 & 0.94 \\
\hline $\mathrm{AC}$ & 35 & 48 & 31 & 10.66 & 0.82 \\
\hline BL & 46 & 50 & 18 & 22.04 & 0.95 \\
\hline $\mathrm{JB}$ & 38 & 42 & 19.5 & 30.90 & 0.91 \\
\hline $\mathrm{BR}$ & 34 & 43 & 30 & 24.28 & 0.82 \\
\hline $\mathrm{GC}$ & 36 & 47 & 25 & 10.58 & 0.90 \\
\hline$\overline{\mathrm{X}} \pm \mathrm{SE}$ & $38.5 \pm 1.5$ & $47.9 \pm 3.8$ & $28.7 \pm 4.1$ & $20.41 \pm 3.09$ & \\
\hline \multicolumn{6}{|l|}{ Group 3} \\
\hline HS & 52 & 54 & 26 & 8.07 & 0.97 \\
\hline SH & 57 & 82 & 18 & 4.68 & 0.94 \\
\hline $\mathrm{AB}$ & 65 & 63 & 20 & 3.93 & 0.95 \\
\hline RV & 65 & $\tilde{55}$ & 37.5 & 2.93 & 0.92 \\
\hline BT & 52 & 72 & 46 & 7.96 & 0.97 \\
\hline $\mathrm{RR}$ & 50 & 55 & 39 & 4.42 & 0.98 \\
\hline AS & 58 & 56 & 24 & 4.68 & 0.96 \\
\hline $\bar{X} \pm S E$ & $57 \pm 2.3$ & $62.4 \pm 4.1$ & $30.1 \pm 4.1$ & $5.24 \pm 0.75$ & \\
\hline
\end{tabular}

\section{SUMMarY}

The relationship of age to baroreceptor reflex activity was determined in 35 healthy volunteers ranging in age from 19 to 65 years. Intra-arterial catheters were placed and blood pressure and pulse rate responses of each subject were observed during a Valsalva maneuver ( 31 subjects) and during the Pressor Test (33 subjects). The Valsalva maneuver consisted of a forced expiration sufficient to raise 
a column of mercury 40 torr for 10 seconds. This resulted in a reduction in pulse pressure (Baroreceptor stimulus) during the maneuver followed by a transient overshoot in diastolic pressure (response) following its termination. In comparison to younger subjects, older subjects had a greater reduction in pulse pressure but similar overshoot in diastolic pressure. The pressor test consisted of observing the effect of increasing systolic blood pressure (stimulus) on pulse duration (response) following the intravenous administration of phenylephrine. By relating each systolic pressure to the immediately succeeding R-R interval, a linear relationship was found. Its slope expressed in milliseconds of R-R interval change per torr increase in systolic pressure is an index of baroreflex function. Older subjects have less cardiac slowing compared to younger subjects and a hyperbolic relationship exists between age and slope $(\mathrm{r}=0.84, \mathrm{p}<0.05)$. These tests indicate that baroreceptor reflex function decreases with aging.

\section{RÉSUMÉ}

Notre étude sur l'activité réflexe baroréceptrice en fonction de l'âge a porté sur 35 volontaires en bonne santé et âgés de 19 à 65 ans.

Après mise en place de canules artérielles, l'on a enregistré la pression et la fréquence cardiaque au cours d'une manœuvre de Valsalva, chez 31 sujets et durant un test d'hypertension chez 33 sujets.

La manœuvre de Valsalva consistait pour fins de cette étude en une expiration forcée suffisante pour élever une colonne de mercure de 40 torr durant 10 secondes. L'on observait dans ces circonstances une chute de la pression différentielle (stimulus) suivie d'une élévation passagère de la pression diastolique survenant à la fin de la manœuvre (réponse). Par comparaison aux plus jeunes, les plus vieux sujets montraient une plus grande diminution de la pression différentielle, mais leur élévation de la diastolique (réponse) était comparable.

Le test d'hypertension consistait à élever les effets de l'élévation de la pression systolique (stimulus) consécutive à l'administration intraveineuse de Phenylephrine, sur la fréquence cardiaque. Les modifications de l'espace RR (en millisecondes) inscrites en fonction de l'élévation de la pression (torr) permettaient d'établir une relation linéaire témoin de la fonction baroréflexe. Les sujets plus âgés ont montré moins de ralentissement de la fréquence en fonction de l'élévation de la pression. Ces tests indiquent que l'activité baroréflexe diminue avec l'âge.

\section{ACKNOWLEDGMENTS}

The authors wish to thank Mr. Wayne Pucci and Mrs. Frances Smith for their excellent technical assistance and Dr. R. M. Cherniak, for the use of his laboratory facilities.

\section{REFERENCES}

1. Heyman, C. \& Neil, E. Reflexogenic areas of the cardiovascular system (London, J. \& A. Churchill Ltd. 1958).

2. Burton, A.C. Physiology and biophysics of the circulation. Year Book, Medical Publishers Incorporated, p. 173 (1965). 
3. Rushmer, R.F. Cardiovascular dynamics. Philadelphia, W.B. Saunders Co. Pp. 168-173 (1970).

4. Tuckman, J., Slatter, S.R., et al. The carotid sinus reflexes. Am. Heart J. 170: 119-135 (1965).

5. Brandfonbrener, M., Landowne, M., \& SHock, N. Changes in cardiac output with age. Circulation 12: 557-566 (1955).

6. Russek, H.I., Rath, M.M., Zohman, B.L., \& Miller, I. The influence of age on blood pressure. Am. Heart J. 32:468-479 (1946).

7. Granath, A., Jonsson, B., \& Strandell, T. Circulation in healthy old men, studied by right heart catheterization at rest and during exercise in supine and sitting position. Acta Medica Scand. 176: fasc. 4: 425-446 (1964).

8. Landowne, M., Brandfonbrener, M., \& Shock, N. W. The relation of age to certain measures of performance of the heart and the circulation. Circulation 21:567-576 (1955).

9. BENDER, D.A. The effect of increasing age on the distribution of peripheral blood flow in man, Am. Geriatrics Society J. 13: 192-198 (1965).

10. McDonald, R.K., Solomon, D.H., \& Shock, N.W. Aging as a factor in the renal hemodynamic changes induced by a standardized pyrogen. J. Clin. Invest. 30: 457-462 (1951).

11. Montoye, H.J., Willis, P.W., III, \& Cunningham, D.A. Heart rate response to submaximal exercise; relation to age and sex. J. Geriontol 23: 127-133 (1968).

12. O’Rourke, M.F., Blazex, J.V., Monreels, C.L. Jr., \& Krovetz, L.J. Pressure wave transmission along the human aorta. Circulation 23: 567-579 (1968).

13. Roach, M.R. \& Burton, A.C. The effect of age on the elasticity of human iliac arteries. Canad. J. Biochem. Physiol. 37: 557-570 (1959).

14. Nornis, A.H., Shock, N.W., \& Yiengst, M.J. Age changes in heart rate and blood pressure responses to tilting and standardized exercise. Circulation 8: 521-526 (1953).

15. WADE, J.G., LARSON, P.C., et al. Effect of carotid endarterectomy on carotid chemoreceptor and baroreceptor function in man. New Eng. J. of Med. 282: 823-829 (1970).

16. Bristow, J.D., Honour, A.J., et al. Diminished baroreflex sensitivity in high blood pressure. Circulation 39: 48-54 (1969).

17. EckberG, D.L., Drabinsky, M., \& Braunwald, E. Defective cardiac parasympathetic control in patients with heart disease. New Eng. J. of Med. 285: 877-883 (1971).

18. Gribin, B., Pickering, T.G., Sleight, P., \& Peto, R. Effect of age and high blood pressure on baroreflex sensitivity in man. Circulation Research 29: 424-431 (1971).

19. Sharpey-SCHAFER, E.P. Effects of Valsalva's maneuver on the normal and failing circulation. Brit. Med. J. 1: 693-695 (1955).

20. Smyth, H.S., Sleicht, P., \& Pickening, G.W. Reflex regulation of arterial pressure during sleep in man. Cir. Res. 24: 109-121 (1969).

21. Appenzeller, O. \& Descarries, L. Circulatory reflexts in patients with cerebrovascular disease. New Eng. J. of Med. 271: 820-823 (1964).

22. Price, H.L., King, B.D., Elder, J.D., et al. Circulatory effects of raised airway pressure during cyclopropane anesthesia in man. J. Cl. Invest. 30(11): 1243-1249 (1951).

23. Price, H.L., Conner, E.H., \& Dripps, R.D. Some respiratory and circulatory effects of mechanical respirators. J. Appl. Physiol. 6(9): 517-530 (1954).

24. ShARPEY-Schafer, E.F. \& TAYLOR, P.J. Absent circulatory reflexes in diabetic neuritis. Lancet 559-562, March (1960).

25. Barraclough, M.A. \& Sharpey-Schafer, E.P. Hypotension from absent circulatory reflexes: effects of alcohol, birbiturates, phychotherapeutic drugs, and other mechanisms. Lancet 1121-1126, May (1963).

26. Cudxowicz, L. Normal pharmacological and disordered systemic circulatory responses to the Valsalva maneuver. Respiration 25: 81-115 (1968).

27. Price, H.L. \& Conner, E.H. Certain aspects of the hemodynamic response to the Valsalva maneuver. J. Appl. Physiol. 5: 449-456 (1953).

28. Howard, P., Leathart, G.L., et al. The "mess trick" and the "fainting lark". Brit. Med. J. 382-384 Aug. ( 1951 ).

29. Rushmer, Robert F. Circulatory effects of three modifications of the Valsalva experiment. Am. Heart J. 399-418.

30. Bristow, J.D., Brown, E.B. JR., Cunningham, D.J.C., Goode, R., Howson, M.G. \& SLEICHT, P. Influence of ventilation, carbon dioxide and hypoxia on the baroreceptor reflex in man. J. Physiol. (Lond.) 198: 102-104 (1968).

31. Duke, P.C., Fownes, D., \& WADE, J.G. The effect of halothane anesthesia on baroreflex function in man. To be published. 
32. Bristow, J.D., Prys-Roberts, C., Fisher, A., Pickering, T.G., \& Sleight, P. Effects of anesthesia on baroreflex control of heart rate in man. Anesthesiology 31:422-428 (1969).

33. Mittler, G. \& WADE J. The effect of methoxyflurane on baroreflex control of heart rate in man. The Canad. Anesth. Soc. J. 19: 60-65 (1972).

34. Krozker, E.J. \& Wood, E.H. Comparison of simultaneously recorded central and peripheral arterial pressure pulses during rest, exercise and tilted position in man. Circulation Research III: 623-632 (1955).

35. O'Rourke, M.F., Blazek, J.V., Morneels, C.L. Jr, \& Krovetz, L.J. Pressure wave transmission along the human aorta. Circ. Research XXIII: 567-579 (1968).

36. O'Rourke, M.F. Pressure and flow waves in systemic arteries and the anatomical design of the arterial system. J. of Appl. Physiol. 23: 139-149 (1967).

37. Blumenthal, H.T., Lansing, A.I. \& Gray, S.H. The interrelation of elastic tissue and calcium in the genesis of arteriosclerosis. Am. J. Path. 26:989-1004 (1950).

38. Learoyd, B.M. \& TAYLOR, M.G. Alterations with age in the visoelastic properties of human arterial walls. Circulation Research XVIII: 278-292 (1966).

39. RoAch, M.R. \& Burton, A.C. The effect of age on the elasticity of human iliac arteries. Can. J. Biochem. Physiol. 37: 557-570 (1959).

40. Muratori, G. Histological observations on the structure of the carotid sinus in man and mammals. Baroreceptors and hypertension. Edited by P. Kezdi. Oxford, Pergamon Press 253-265 (1967).

41. Muratori, G. Histopathological observations in man. Arch. Int. Pharmacodyn, 152: 98105 ( 1964).

42. Abraham, A. The structure of baroreceptors in pathological conditions in man. Baroreceptors and hypertension, Edited by P. Kezdi, Oxford, Pergamon Press 273-291 (1967).

43. Gebmer, G.L. The central organization of the baroreceptor reflexes, Anesthesiology 32 : 193-195 (1970).

44. Cenber, G.L. \& Snyder, D.W. Hypothalmic control of baroreceptor reflexes. Am. J. of Physiol. 218: 124-131 (1970).

45. Hinton, S.M. Inhibition of baroreceptor reflexes on hypothalmic stimulation. J. Physiol. London, 165: 56 (1963).

46. Hockaran, C.H., Talesnik, J., \& Livingston, K.E. Central nervous system modulation of baroreceptor reflexes. Am. J. Physiol. 217: 1681-1689 (1969).

47. Monuzzi, G. Paleocerebellar inhibition of vasomotor and respiratory carotid sinus reflexes. J. Neurophysiol. 3: 20-32 (1940).

48. SMIth, O.A. \& NATHAN, M.A. Inhibition of the carotid sinus reflex by stimulation of the inferior olive. Science 154:674-675 (1966).

49. Kevans, L.R. \& Gebber, G.L. Facilitatory forebrain influence on cardiac component of baroreceptor reflexes. Am. J. Physiol. 219: 1235-1241 (1970).

50. Andrew, W. Structural alterations with aging in the nervous system. J. Chron. Dis. 3: 575-596 (1956).

51. VoGt, C. \& VoGT, O. Aging of nerve cells. Nature, London 158: 3-4 (1946).

52. Kuntz, A. \& Sulkin, N.M. (b) Hyperplasia of peripheral neuroglia: a factor in pathological changes in autonomic galglia. J. Neuropath. and Exper. Neurol. 6: 323-332 (1947).

53. Staffond, H. \& Gelhonn, E. Age and autonomic balance. Proc. Soc. Exp. Biol. N.Y. 60: 98-101 (1945).

54. Nelson, R. \& Gelmonn, E. The influence of age and functional neuropsychiatric disorders on sympathetic and parasympathetic function. J. Psychosomatic Res. 3: 12-26 (1958).

55. Crawford, J.H. The influence of the vagus on the heart rate. J. of Pharm. and Exper. Therap. 22: 1-19 (1924). 